NASA Technical Memorandum 4320

\title{
A Preliminary Investigation of the Use of Throttles for Emergency Flight Control
}

F. W. Burcham, Jr., C. Gordon Fullerton, Glenn B. Gilyard, Thomas D. Wolf, and James F. Stewart

Dryden Flight Research Facility

Edwards, California

\section{N/SA}

National Aeronautics and Space Administration

Office of Management

Scientific and Technical Information Program 
$\bar{\tau}$ 


\title{
A PRELIMINARY INVESTIGATION OF THE USE OF THROTTLES FOR EMERGENCY FLIGHT CONTROL
}

\author{
F.W. Burcham, Jr.* \\ C. Gordon Fullerton \\ Glenn B. Gilyard \\ Thomas D. Wolf \\ James F. Stewart \\ NASA Dryden Flight Research Facility \\ Edwards, California
}

\begin{abstract}
A preliminary investigation was conducted regarding the use of throttles for emergency flight control of a multiengine aircraft. Several airplanes including a light twin-engine piston-powered airplane, jet transports, and a high performance fighter were studied during flight and piloted simulations. Simulation studies used the B-720, B-727, MD-11, and F-15 aircraft. Flight studies used the Lear 24, Piper PA-30, and F-15 airplanes. Based on simulator and fight results, all the airplanes exhibited some control capability with throttles. With piloted simulators, landings using manual throttles-only control were extremely difficult. An augmented control system was developed that converts conventional pilot stick inputs into appropriate throttle commands. With the augmented system, the B-720 and F-15 simulations were evaluated and could be landed successfully. Flight and simulation data were compared for the F-15 airplane.
\end{abstract}

\section{Nomenclature}

$\begin{array}{ll}\text { CAS } & \text { control augmentation system } \\ \text { c.g. } & \text { center of gravity } \\ \text { Fex } & \text { excess thrust, lb } \\ \mathrm{K} & \text { gain constant } \\ \mathrm{K}_{\mathrm{p}} & \text { roll rate feedback gain, } \mathrm{deg} / \mathrm{sec} \\ \mathrm{K}_{\mathrm{q}} & \text { pitch rate feedback gain, deg/sec }\end{array}$

*Chief, Propulsion Branch. Associate Fellow, AIAA.

Copyright (C) 1991 by the American Institute of Aeronautics and Astronautics, Inc. No copyright is asserted in the United States under Title 17, U.S. Code. The U.S. Government has a royalty-free license to exercise all rights under the copyright claimed herein for Governmental purposes. All other rights are reserved by the copyright owner.

$\begin{array}{ll}\mathrm{K}_{\boldsymbol{\beta}} & \text { sideslip feedback gain, deg } \\ \mathrm{K}_{\boldsymbol{\gamma}} & \text { flightpath angle feedback, deg } \\ \mathrm{K}_{\boldsymbol{\phi}} & \text { bank angle feedback gain, deg } \\ \text { LDP } & \text { landing difficulty parameter } \\ \text { PLA } & \text { power lever angle, deg } \\ \text { PLF } & \text { power for level flight } \\ \text { VC } & \text { calibrated airspeed, knots } \\ \Delta & \text { change }\end{array}$

\section{Introduction}

In an emergency, throttles may be used for augmenting or replacing aircraft flight control systems. Aircraft flight control systems are extremely reliable. Multiple control surfaces, hydraulics, sensors, control computers, and control cables are used to achieve high levels of control system redundancy and reliability. However, during extremely rare occasions potentially disastrous flight control system failures do occur. This is particularly true for military airplanes operating in a hostile environment. At such times, any other form of flight control, including propulsion, would be welcome.

Some aircraft with multiple engines may be controlled to a rudimentary degree with the throttles. The use of differential thrust induces yaw and the dihedral effect results in roll. Many transport airplanes exhibit nose-up pitching moments from thrust increases that may be useful for pitch control. In addition, most airplanes have positive speed stability (if speed increases, the airplane will climb, and if speed decreases, the converse occurs). Airplanes have flown with total hydraulic system failures for substantial periods using only engines for control. ${ }^{(1,2)}$ In addition, engine 
control augmented the flight controls in a L-1011 airplane that experienced a hardover stabilizer failure. ${ }^{(3)}$

The NASA Dryden Flight Research Facility (NASA Dryden) has been the site for conducting preliminary flight, ground simulator, and analytical studies of propulsion system use for control. The objective has been to determine the degree of control power available with the throttles for various classes of airplanes. In addition, the development of possible control modes for future airplanes has been investigated. The most likely control failures involve partial loss of flight controls. However, in most cases, it is assumed that a complete failure occurred with the flight control surfaces (elevator, rudder, aileron) in the locked position.

Several airplanes were studied, based primarily on availability. Simulation studies were conducted on the B-720, MD-11, F-15, and B-727 aircraft. Cursory flight evaluations were flown in the Lear 24, PA-30, and F-15 airplanes. These airplanes showed some degree of throttles-only controllability. An augmented control system for the B-720 and F-15 airplanes was designed and tested using piloted ground simulators. The augmented system design and its application to the B-720 airplane is included in Ref. 4.

This paper will present some preliminary ideas and information on the feasibility of using engine thrust to supplement or replace the flight control system. Selected results from the piloted simulator studies of the B-720, B-727, MD-11, and F-15 airplanes will be presented, including the augmented control results for the F-15 airplane. Limited flight evaluations on the Lear 24, PA-30, and F-15 aircraft are discussed. Flight and simulator test results will be compared for the F-15 airplane. Also presented are simple methods for correlating propulsive control capability with airplane characteristics.

\section{Principles of Engines-Only Controls}

Engine thrust can be used to control the heading and flightpath of a multiengine airplane. This section presents the principles of engines-only flight control; first, for roll control, then for the more complex pitch control, and finally, for specd control.

\section{Yaw-Roll}

Differential thrust generates sideslip, which through the normal dihedral effect present on most airplanes results in roll. The dihedral effect tends to be larger with greater wing sweep angle. Roll from differential thrust is controlled to establish a bank angle, which results in a turn and change in aircraft heading. Some airplanes exhibit a coupled mode between roll and yaw called dutch roll, in which the nose traces an elliptical path. Dutch roll can cause control difficulties.

\section{Pitch}

Pitch control caused by throttle changes is more complex. There are several effects that may be present, depending on the aircraft characteristics. The desired result is to stabilize and control the vertical flightpath.

\section{Phugoid}

The phugoid is the longitudinal long-period oscillation of an airplane. It is an approximately constant angle-of-attack motion trading speed for altitude. The degree of oscillation in speed and altitude relates to the speed stability. Once excited by a pitch or thrust change, the phugoid will be initiated with a period of approximately $1 \mathrm{~min}$ and it may or may not damp naturally. The period is a function primarily of speed and not aircraft design. Properly sized and timed throttle inputs can be used to damp unwanted phugoid oscillations.

\section{Flightpath Angle Change Caused by Speed Stability}

The initial response to the phugoid may be used for flightpath control. Most airplanes exhibit positive speed stability. A thrust increase will cause, in the short-term, a speed increase that will cause a lift increase, which will cause the flightpath angle increase. In the longer term, the phugoid will cause speed to oscillate around the initial velocity. Angle of attack remains essentially constant. The degree of speed stability, and the resulting pitch motions are affected by aircraft configuration and the center of gravity (c.g.) location. 


\section{Pitching Moment Caused by Thrust Line Offset}

If the engine thrust line does not pass through the c.g., there will be a pitching moment introduced by thrust change. For many transport aircraft, the thrust line is below the c.g. Increasing thrust results in a noseup pitching moment, with the magnitude being a linear function of the thrust change. This is the desirable geometry for throttle-only control, because a thrust change immediately starts the nose in the same direction needed for the long-term flightpath angle change. High-mounted engines result in this effect fighting the speed stability effects. Pitching moment caused by thrust will cause a change in the trimmed angle of attack and airspeed as well as changing the long-term flightpath angle.

\section{Flightpath Angle Change Caused by the Vertical Component of Thrust}

If the thrust line is inclined to the flightpath, an increase in thrust will result in a direct increase in vertical velocity, that is, rate of climb. This also will occur at constant angle of attack. For a given aircraft configuration, this effect will increase as angle of attack increases (that is, as speed decreases).

\section{Speed Control}

Once the normal flight control surfaces (elevator, rudder, aileron) become locked, the trim airspeed of most airplanes is affected only slightly by engine thrust. Retrimming to a different speed may be achieved by other techniques. These techniques include: moving the c.g., lowering the flaps and landing gear, and by using stabilizer trim, if available. Generally, the speed needs to be reduced to an acceptable landing speed; this implies developing nose-up pitching moments. Methods for accomplishing this include moving the c.g. aft and selective lowering of flaps. In aircraft with more than two engines, speed can be reduced by increasing the thrust of low-mounted engines. The retrimming capability will vary widely between airplanes.

\section{Flight Research Studies}

Some preliminary flight research studies were conducted on three airplanes covering a range of airplane types and sizes: the F-15, the Lear 24, and the PA-30 aircraft.

\section{F-15 Air Superiority Fighter}

The F-15 airplane (McDonnell Douglas Corporation, St. Louis, Missouri), Fig. 1 and Table 1, is a high performance fighter with a maximum speed capability of Mach 2.5. It has a high wing with $45^{\circ}$ of leadingedge sweep and twin vertical tails. It is powered by two F100 (Pratt and Whitney, West Palm Beach, Florida) afterburning turbofan engines mounted close together in the aft fuselage. The thrust-to-weight ratio is very high, approaching 1 at low altitudes. The engine response is fast, $3 \mathrm{sec}$ from idle to intermediate power. The F-15 airplane has a mechanical flight control system augmented with a high-authority electronic control augmentation system. Hydraulic power is required for all flight control surfaces.

Flight tests used the NASA F-15 airplane. Although the engines are very close to the centerline, the F-15 airplane exhibits significant rolling as a result of differential thrust. Roll rates with full differential thrust are approximately $7.5 \mathrm{deg} / \mathrm{sec}$ at $300 \mathrm{knots}$, increasing to $17 \mathrm{deg} / \mathrm{sec}$ at $170 \mathrm{knots}$. In pitch, at a speed of 300 knots, there is no pitching moment as a result of thrust and the speed stability is neutral. When trimmed for 170 knots, there is significant pitch authority. Figure 2 shows the pitch axis response, at 170 knots, for a change in power setting from power for level flight (PLF) to intermediate (maximum nonafterburning) power. During the first second there is essentially no airplane response. Total thrust for the two engines is shown; the engines respond rapidly, with most of the thrust change occurring within $1.5 \mathrm{sec}$. As speed increases, pitch rate increases, reaching a value of $2 \mathrm{deg} / \mathrm{sec}$ at $10 \mathrm{sec}$ after the throttle advance. The flightpath angle has increased by $5^{\circ}, 5 \mathrm{sec}$ after the throttle advance. At approximately $12 \mathrm{sec}$, the phugoid response causes the speed to begin dropping; it would eventually return, in an oscillatory fashion, to the trim speed.

In flight tests, three pilots evaluated the controllability of the F-15 airplane with throttles only, leaving the stick and rudder centered. The control augmentation system (CAS) was turned off, because it tended to remove sideslip caused by differential thrust. With the CAS off, and using only manual throttle control, pilots could roll the airplane, hold a bank angle and assigned heading. If the airplane was trimmed at 170 knots, adequate pitch control was available to hold altitude within approximately $100 \mathrm{ft}$. 
If a flight control failure occurred at higher speeds, some method would be necessary to retrim the F-15 airplane to lower speeds. Use of fuel transfer to move the c.g. aft would be one way to develop nose-up pitching moments, which would slow the F-15 airplane. Moving from nominal to full-aft c.g. would slow the trim airspeed by approximately 100 knots. The ramps of the variable capture inlets are also useful in generating nose-up moments. These would allow an approximately $30-\mathrm{knot}$ reduction in trim airspeed if placed in the emergency full-up position. Extension of the landing gear results in almost no change in speed on the F-15 airplane.

\section{Lear 24 Executive Jet Transport}

The Lear 24 airplane (Gates Learjet, Wichita, Kansas), Fig. 3 and Table 1, is a twin-engine business jet. The low-mounted wing has $13^{\circ}$ of sweep. The engines, GE CJ610 turbojets (General Electric, Lynn, Massachusetts) with 2,900-lb thrust each, are mounted high on the aft fuselage. The airplane has a $\mathrm{T}$ tail arrangement. Maximum weight is $11,800 \mathrm{lb}$. The Lear 24 airplane has a thrust-to-weight ratio of approximately 0.5 . The turbojet engines respond rapidly to throttle changes, $2.5 \mathrm{scc}$ from idle to full thrust.

The airplane used in this first evaluation was the Calspan variable stability airplane. It is equipped with the basic Lear 24 mechanical control system, including an electric stabilizer pitch trim capability. In addition, there are hydraulic actuators that add electrical inputs from the variable stability system to the mechanical system.

The basic Lear 24 characteristics with throttles-only control were investigated at a speed of approximately 200 knots. Roll control power is large, roll rates in excess of $25 \mathrm{deg} / \mathrm{sec}$ can be obtained with full differential thrust, even with the yaw damper engaged. Time to bank from level flight to $30^{\circ}$ was $4 \mathrm{sec}$.

The basic Lear 24 pitch control capability was also investigated. In contrast to the roll axis, pitch control with thrust was very difficult. Because of the high engine placement, a thrust increase caused a nose-down pitch. Eventually, the speed stability would bring the nose back up. Time to achieve a $5^{\circ}$ pitch increase was $21 \mathrm{sec}$. Reducing thrust caused a slight pitchup, followed by a pitch down as speed decreased. It took $23 \mathrm{sec}$ to achieve a $5^{\circ}$ pitch decrease. It was extremely difficult to control pitch. The phugoid was very dif- ficult to damp with throttle inputs. Despite this, the Lear 24 airplane was flown in up-and-away flight for 20 min using only the throttles. Roll and heading were controlled precisely, and altitude was maintained within $500 \mathrm{ft}$.

\section{PA-30 Piston-Powered Light Twin-Engine Plane}

The Piper PA-30 airplane (Piper Aircraft Corporation, Vero Beach, Florida), Fig. 4, is a light twinengine four-place airplane. It has a low-mounted unswept wing, and the engines are mounted ahead of the wing in nacelles. Maximum weight is $3,600 \mathrm{lb}$. The engines are the Lycoming IO-320 (Textron Lycoming, Williamsport, Pennsylvania; formerly Avco Lycoming) rated at $160 \mathrm{hp}$ each.

The PA-30 airplane was flown with throttles only and it had significant control power. However, it was very difficult to control. The roll control on the PA-30 airplane is highly nonlinear. It appears that the major rolling moment is caused by reducing the throttle on one side until the blowing over the wing is sharply reduced. The linear response to differential thrust seen on other jet-powered airplanes was not present. Maximum roll rates were approximately $10 \mathrm{deg} / \mathrm{sec}$, but came only with one engine near idle power. Pitch control is difficult. There is adequate control power available from speed stability, but the longitudinal phugoid is hard to damp. Overall, it was possible to maintain gross control of heading and altitude, but landing on a runway would be extremely difficult.

\section{Simulator Studies}

Piloted simulator studies of engines-only flight control capability were conducted on the B-720, B-727, MD-11, and the F-15 aircraft. One task evaluated was "up-and-away" control. This was the ability to control heading to within a few degrees, and to control altitude to within $\pm 200 \mathrm{ft}$. The other task was landing on a runway.

\section{B-720 Commercial Jet Transport}

The Boeing 720 airplane (Boeing Company, Seattle, Washington), Fig. 5, is a four-engine transport designed in the late 1950 's. It has a $35^{\circ}$ swept wing mounted low on the fuselage, and four engines mounted on pods below and ahead of the wing. The engines are Pratt and Whitney (East Hartford, Connecticut) JT3C- 6 turbojets. The airplane is equipped with a conventional flight control system 
incorporating control cables and hydraulic boost. It also incorporates a slow-rate electric stabilizer trim system. The flaps are electrically controlled.

A high-fidelity B-720 engineering simulation was available at NASA Dryden from the Controlled Impact Demonstration (CID) flight program conducted jointly by NASA and the Federal Aviation Administration (FAA). The B-720 simulation included nonlinear aerodynamic derivatives, including ground effect. The simulation was modified to permit locking of all the flight control surfaces at a desired condition. This would simulate the situation that results in more modern airplanes with a total hydraulic system failure. The throttles were then available for flight control. The simulation was mechanized using a twin-engine fighter engineering cockpit. Because of this, inboard and outboard engines on each side were controlled by a single throttle. However, the pitching and yawing moments caused by each of the four engines were modeled individually.

A discussion of the manual throttles-only simulation results and the design, development, and evaluation of an augmented control system for the B-720 airplane are included in Ref. 4 . The control modes are described briefly here.

The pilot of the B-720 simulation flew manually using the throttles only. Good roll capability was evident, with roll rates of approximately $20 \mathrm{deg} / \mathrm{sec}$. Good pitch capability also was found, with some pitching moment because of the thrust line being below the c.g., and also pitching moment caused by speed stability. Pitch rate at $160 \mathrm{knots}$ was $1.8 \mathrm{deg} / \mathrm{sec}$, and at $200 \mathrm{knots}$ it was $1.1 \mathrm{deg} / \mathrm{sec}$.

With this control power it was possible for a pilot to maintain gross control, hold heading and altitude, and make a controlled descent. However, it was extremely difficult for a pilot to make a landing on a runway. There was a 1-sec lag in pitch and roll before the airplane began to respond to the throttles. Judging the phugoid damping was difficult, and the lightly damped dutch roll was a major problem in roll and heading control. Although a few pilots did develop techniques for successful landings using manual throttles, most were unable to make repeatable successful landings.

An augmented control mode, Fig. 6, was developed for the B-720 airplane. The control mode used pilot stick inputs, with appropriate gains and feed- back parameters, and drove the throttles. The pilot commanded a flightpath angle, and the throttles were driven collectively to achicve the flightpath angle. The control for the roll axis was mechanized using differential throttle to command yaw, and hence, through dihedral effect, roll. Two types of roll control were evaluated. In one, bank angle was commanded by lateral stick position, in the other, roll rate was commanded. The dutch roll mode was welldamped by the roll rate command system, but there was an unstable spiral mode. The bank angle command mode was less effective in dutch roll damping, making control more difficult, particularly in turbulence, but it would hold a bank angle well.

Using the augmented control mode, it was possible for a pilot to make successful landings. Pilot proficiency improved rapidly with time, as the lead required to compensate for the slow engine response was learned. Landings without turbulence or with light turbulence were generally good. With moderate turbulence pilot ratings degraded, but most landings were still successful. Pilot ratings for the manual and augmented control modes are presented in Ref. 4.

Another control mode developed was an "autoland" system that uses instrument landing system (ILS) error signals to command the engines. The automatic system makes small corrections to null errors before they become appreciable. This better accommodates the slow response of the engines and provides good and repeatable landings. The autoland system can handle moderate levels of turbulence much better than a pilot can. Reference 4 provides a more detailed description of the B-720 airplane, the augmented control system, the autoland system, and the results of the piloted simulation studies.

\section{B-727 Commercial Jet Transport}

Figure 7 shows the Boeing 727 three-engine transport airplane, which is capable of carrying up to 150 passengers. It has a swept wing and a $T$ tail. The three Pratt and Whitney (East Hartford, Connecticut) JT8D low-bypass-ratio turbofan engines are mounted in the aft fuselage. The two outboard engines are mounted on short pylons, while the center engine is located in the aft fusclage and has an inlet above the fuselage. The engine response was slow $(3 \mathrm{scc})$ from idle to an engine pressure ratio of 1.2 , then fast $(3 \mathrm{sec}$ to reach full thrust). 
The B-727 engines-only control was evaluated in a motion-based simulation at the NASA Ames Research Center at a speed of approximately 200 knots. In an evaluation of engines-only roll rate, with the outboard engines at full differential thrust, roll rates of 4 to $5 \mathrm{deg} / \mathrm{sec}$ were obtained. There was a $1-\mathrm{sec}$ lag before the roll rate was appreciable. From an initial wingslevel condition, it took $11 \mathrm{sec}$ to reach a $30^{\circ}$ bank. In $4 \mathrm{sec}$, the bank angle was approximately $12^{\circ}$. This roll capability, while much less than the F-15 or B-720 airplanes, was surprisingly large considering the fuselage mounting of the engines.

Pitch control power was also evaluated. There is significant pitching authority with thrust on the B-727 airplane. With the airplane trimmed and throttles set for level flight, nose-up pitch rates at full thrust were approximately $0.75 \mathrm{deg} / \mathrm{sec}$; nose-down pitch rates at idle were $0.4 \mathrm{deg} / \mathrm{sec}$.

These pitch and roll control power values are smaller than those for the B-720 simulation and slow in initial response. Precise control of flightpath angle using throttles was difficult. Use of electric stabilizer trim was more successful.

The airplane was flown using differential engine thrust for bank angle and electric trim in pitch, and gross control was possible. After a 10-min period of familiarization, it was possible to hold heading within approximately $2^{\circ}$ and altitude to within $100 \mathrm{ft}$.

Landings were attempted using differential throttle and electric trim. Neither of the evaluation pilots could successfully land the airplane on the runway by themselves. The low roll rate and roll control lag made it extremely difficult to remain lined up with the runway. It was possible to keep control, but not with sufficient precision to land on a runway. It was possible to make a well-controlled touchdown assuming an "infinite" (unlimited length and width) runway.

Improved roll control was achieved by reducing the center engine throttle to idle; the higher thrust and the faster thrust response of the outboard engines improved directional control. Splitting the control task between two pilots also helped. One pilot would fly pitch with electric trim, while the other pilot used differential throttles for roll and heading control. Even with this technique, it was not possible to make consistent landings on the runway.

\section{F-15 Air Superiority Fighter}

A simulator study was performed on the NASA F-15 airplane. The simulation was a high fidelity nonlinear piloted simulation valid over the full flight envelope. It was flown in a simulator cockpit with actual F-15 stick and throttles. A visual scene, including the Edwards runways, was provided on a video monitor.

The initial simulation results showed roll rates of 10 to $20 \mathrm{deg} / \mathrm{sec}$ over much of the flight envelope, and essentially no pitch capability at 300 knots. Below 250 knots, the simulator showed increasing pitch authority. This was partly because of the increasing angle of attack, which would provide an increasing component of thrust in the lift direction, and also increased speed stability.

Roll characteristics were evaluated, and found to be good. There was no roll response during the first second, but roll rate increased rapidly thereafter. Roll rates from flight test results were compared to NASA Dryden simulator roll rates. Figure 8 shows maximum roll rate as a function of airspeed (VC) for idle power on one engine and intermediate power (maximum nonafterburning) on the other engine. At VC $=300$ knots, the flight values were approximately 75 percent of the simulation values. To resolve this discrepancy, the McDonnell Douglas F-15 piloted simulator was also used, and roll rates were similar to the NASA simulation. Unmodeled effects of unequal engine power settings in both simulators may be the cause of this discrepancy. At lower speeds, this discrepancy was smaller, and the roll rates were higher. At 170 knots, the flight roll rates were $17 \mathrm{deg} / \mathrm{sec}$, while the simulator yielded values of $20 \mathrm{deg} / \mathrm{sec}$. The engine thrust lateral offset was reduced to make the simulator roll rate match the flight roll rate for all data shown hereafter.

Pitch rate was also evaluated in the simulator. There was no pitch response during the first second. At 170 knots, when the throttle was increased from PLF to intermediate power, the maximum pitch rate was $2 \mathrm{deg} / \mathrm{sec}$. Going from PLF to idle, the pitch rate was $-0.6 \mathrm{deg} / \mathrm{sec}$. Figure 9 compares the flight and simulation pitch results as a function of speed, and shows excellent agreement. The low pitch-down capability relative to the pitchup capability is because the throttle setting for PLF is much closer to idle than to intermediate. 
Both the roll rate and the pitch rate capability increase as speed decreases. This is believed to result from the decreasing stability of the airplane as the speed decreases. The engine thrust moments are approximately independent of speed. The restoring moments resulting from stability are a function of speed, hence, the control effectiveness of the throttles would increase.

The piloted F-15 simulation was later used in a landing study. With the CAS turned off, the pilots used throttles-only control to fly approaches and landings using the video display of the 15,000-ft-long Edwards runway. Starting at a trimmed condition at 170 knots and 5 miles out, eight consecutive landing approaches were made. Figure 10 shows results of the first several landings for two pilots, plotted with a landing difficulty parameter (LDP). The LDP is a parameter that is the sum of, at touchdown, sink rate in $\mathrm{ft} / \mathrm{sec}$, absolute value of bank angle in degrees, and a touchdown dispersion penalty. The dispersion penalty was 0 on the runway, 5 within $300 \mathrm{ft}$ of the runway, and up to 30 for landings more than $2,000 \mathrm{ft}$ from the runway, as shown. Based on F-15 characteristics, it was felt that LDP values up to 10 would result in a landing with no damage. The LDP values of 15 to 25 would be survivable but damage might occur, and LDP values of 30 and above would definitely result in damage and possible injury.

During the initial landing attempts, control was extremely difficult. The longitudinal phugoid was excited at the initializing point and was a constant problem through touchdown. Throttle inputs to damp the phugoid were hard to judge. Roll control, while adequate in rate, had the troublesome 1-sec lag. The combined task was so difficult that the initial landings had high sink rates and large touchdown dispersions. This resulted in LDP values in the "certain damage" category.

A typical time history of one of these manual landings is shown in Fig. 11. This was a second landing attempt by a pilot with no previous throttles-only landing experience. As the rate of sink increased, the pilot made a proper throttle increase, but in doing so, induced a roll to the right. He then corrected with a roll to the left. Rate of sink again increased, and going through an altitude of $500 \mathrm{ft}$, a large throttle input was made from 53 to $63 \mathrm{sec}$. This resulted in a rapid pitchup with rate of climb becoming positive.
Throttles were then reduced to idle, and a small bank angle correction was made back toward the runway. Again, rate of sink increased, this time a smaller throttle input was tried. However, it was insufficient to prevent hitting the ground at $18 \mathrm{ft} / \mathrm{sec}, 500 \mathrm{ft}$ right and 2,000 ft short of the threshold, for a LDP of 46.

After a few manual throttles-only landings, the proper lag compensation technique for bank angle control was learned. This made it possible to concentrate on pitch control, which is primarily phugoid damping. Techniques for finding the proper degree of throttle input were learned after approximately five landings. For each pilot, the last landings shown in Fig. 10 had acceptable sink rates and bank angles, and were made on the runway. These landings demonstrated the sharp learning curve associated with throttles-only control. In addition, the landings illustrated that adequate control power was available to land the F-15 airplane. Figure 12 shows another time history of the eighth manual throttle landing made by one pilot. There is still significant throttle activity initially. But a proper-sized throttle input at $66 \mathrm{sec}$ effectively damped the phugoid. A $6 \mathrm{ft} / \mathrm{sec}$ rate-of-sink landing with $2^{\circ}$ of bank was made on the center line 2,200 $\mathrm{ft}$ from the threshold for an LDP value of 8 . Considerable throttle activity is evident in the last $20 \mathrm{sec}$ as the pilot worked hard to arrest the rate of sink without ballooning.

The augmented mode developed for the B-720 airplane ${ }^{(4)}$ was incorporated in the F-15 simulator. Gain changes were made to account for the differences in throttle range and thrust, but the basic control concept remained the same as shown in Fig. 6. All the roll feedback gains were set to zero, making the lateral stick command differential thrust directly. Performance in the augmented mode was much improved. The first three augmented landings made by two pilots are shown in Fig. 13, with the data from Fig. 10. One pilot lacked previous time in the F-15 aircraft and simulator, while the other had not flown the F-15 aircraft with throttles only. These augmented landings showed LDP values of 2 to 7, illustrating the much-improved capability. A third time history, Fig. 14, shows the pilot flying his first F-15 simulator landing with augmented control. The throttle excursions are smaller, rate of sink is well-controlled, and the landing is again on the center line 2,000 $\mathrm{ft}$ down the runway. Some overcontrol in roll is evident, but adequate performance was obtained. 
Landings were made with turbulence levels up to moderate, with crosswinds, and flying qualities remained good. The effects of variations in c.g. were also investigated. With full aft c.g. (30 percent), the maximum pitch rate decreased to less than $0.8 \mathrm{deg} / \mathrm{sec}$. This made the landing task much more difficult.

All the landings discussed previously were made from a trimmed initial flight condition in the 150 to $220 \mathrm{knot}$ speed range. If a flight control failure occurs at higher speeds, methods such as c.g. control are necessary to decrease speed to where landing would be practical. Simulated landings were made from initial flight conditions as fast as $\mathbf{3 5 0}$ knots using fuel transfer and inlet ramp control to slow to an acceptable approach speed.

\section{MD-11 Commercial Transport}

The MD-11 airplane (McDonnell Douglas Corporation, Long Beach, California) is a large, long-range commercial transport. It has a $35^{\circ}$ sweep low-mounted wing. It is powered by three high-bypass turbofan engines, two are mounted in underwing pods, and the third is mounted in the base of the vertical tail. The engines are slow to respond at low thrust levels, but respond well above 30 -percent thrust.

The capability for engines-only control of the MD-11 airplane was investigated briefly in flight simulators at 200-knots airspeed. Findings show that substantial but confusing pitch control is available. The center engine produces strong nose-down pitching moment while the wing engines produce weak noseup pitching moment. Using only the wing engines for pitch control results in a maximum pitch rate of $1.5 \mathrm{deg} / \mathrm{sec}$. In roll, the use of differential thrust produces very sluggish roll control, with a maximum roll rate of $3 \mathrm{deg} / \mathrm{sec}$. Control capability at lower speeds was not investigated. The capability may be larger, based on trends of the F-15 airplane.

Up-and-away flying was possible, altitude could be maintained, and heading held within reasonable limits. The low roll rate makes runway lineup very difficult even without any turbulence or crosswind. Landings were attempted in the simulator. While it was possible to come close to the runway, it was not possible to make repeatable controlled landings on the runway.

\section{Roll and Pitch Correlations}

An attempt was made to correlate the control power of the jet airplanes studied. The obvious physical parameters used were those that affect throttles-only control capability, such as weight, span, thrust, thrust offset, and wing sweep.

Factors enhancing roll control include: high-thrust engines, engines mounted far from the fuselage, high wing-sweep angles, low yaw inertia, and low weight. Figure 15 shows a correlation developed using the previously mentioned parameters, and the observed roll rates of several airplanes at a trim airspeed of approximately 200 knots. The parameter has engine differential thrust, thrust moment arm, and a wing-sweep parameter in the numerator and weight and wing span squared in the denominator. The span-squared term is a representation of the yaw and roll inertia. Data for the airplanes studied show an approximately linear variation with roll rate, indicating that the selected parameters include most of the significant effects.

A simple pitch rate correlation was also made, see Fig. 16. The pitch rate correlation parameter has three components: pitch resulting from pitch thrust moment, pitch resulting from speed stability, and pitch resulting from the vertical component of thrust. Excess thrust above that required for level flight is used in this correlation. The maximum pitch rate correlation also shows an approximately linear trend.

\section{Overall Flying Qualities}

Based on the preliminary results of the flight and simulation studies, it appears that many multiengine airplanes can use throttles for emergency flight control. All the airplanes tested can be flown in up-and-away flight, with altitude and heading control possible.

There was an approximately $1-\mathrm{sec}$ time delay in pitch and roll on all airplanes tested. Reference 5 indicates that control system time delays of up to $1 \mathrm{sec}$ may be tolerable for landing large airplanes. Thus, the delay in response to the throttles should not preclude the ability to make emergency throttles-only landings.

The F-15 and B-720 airplane simulations have sufficient control power available to make repeatable runway landings. While manual control is extremely difficult, an augmented control system can make 
runway landings feasible. These two airplanes have pitch rate capability in excess of $1 \mathrm{deg} / \mathrm{sec}$, and roll rate capability in excess of $15 \mathrm{deg} / \mathrm{sec}$. The MD-11 and B-727 aircraft are controllable for up-and-away flight. However, at 200 knots their roll control capability is less than $5 \mathrm{deg} / \mathrm{sec}$, which may be too low for successful manual throttles-only runway landings. Reference 6 indicates that roll rates of more than $10 \mathrm{deg} / \mathrm{sec}$ are required for successful landings. It is possible that an automatic ILS-coupled control system, such as that implemented on the B-720 airplane simulation could accommodate aircraft with low roll rate capability. This would make runway landing feasible.

\section{Concluding Remarks}

Several airplanes were evaluated in a preliminary investigation of the use of throttles for emergency flight control. All the airplanes tested showed some degree of useful control capability with the throttles. All airplanes could be controlled in a gross manner (heading and altitude could be maintained). In most cases, however, the pilot workload would be high.

All airplanes tested were controllable in roll with differential throttle, with maximum roll rates ranging from 3 to $25 \mathrm{deg} / \mathrm{sec}$. In pitch, the Lear 24 airplane (and the F-15 airplane at speeds above 300 knots) had little or no usable control capability. However, the other airplanes tested had useful levels of pitch control capability. For all airplanes tested, there was a 1-sec lag between initial throttle motion and the first pitch or roll response.

Because of the lag associated with the engine thrust response, and the phugoid characteristics, it was very difficult to achieve precise control with manual throttle control. Pilot proficiency improved rapidly with time in some, but not all airplanes.

The flight and simulation pitch and roll characteristics were compared for the F-15 airplane. The pitch rates compared well, but the flight roll rates were significantly less than the simulation results. The simulation was adjusted to match flight for the landing tests.

Augmented control systems were evaluated that used stick commands and feedback parameters to move the throttles during the F-15 and B-720 flight simulations. The augmented modes effectively damped the phugoid and improved the roll characteristics. Acceptable flying qualities for emergency landing were achicved. A first approach to simple correlating parameters based on aircraft physical characteristics was shown to provide an approximately linear relation to pitch rate and roll rate.

\section{References}

1 "Inquiry Committee Analyzes JAL 747 Flight Data Recorder," Aviation Week \& Space Technology, vol. 123, no. 10, Sept. 9, 1985, pp. 97.

2 "United DC-10 Crashes in Sioux City, Iowa," Aviation Week \& Space Technology, vol. 131, no. 4, July 24,1989 , pp. 96-97.

${ }^{3}$ McMahon, Capt. Jack, "Flight 1080," Air Line Pilot, July 1978.

${ }^{4}$ Gilyard, Glenn B., Conley, Joseph L., Le, Jeanette, and Burcham, Frank W., Jr., "A Simulation Evaluation of a Four-Engine Jet Transport Using Engine Thrust Modulation for Flightpath Control," AIAA-91-2223, June 1991.

${ }^{5}$ Grantham, William D., Smith, Paul M., Person, Lee H., Jr., Meyer, Robert T., and Tingas, Stephen A., Piloted Simulator Study of Allowable Time Delays in Large-Airplane Response, NASA TP-2652, 1987.

${ }^{6}$ Holleman, Euclid C., and Gilyard, Glenn B., InFlight Evaluation of the Lateral Handling of a FourEngine Jet Transport During Approach and Landing, NASA TN D-6339, 1971. 
Table 1. Physical characteristics of the airplanes.

\begin{tabular}{lcccccc}
\hline \hline & \multicolumn{7}{c}{ Airplane } \\
\cline { 2 - 7 } & $\mathrm{F}-15$ & Lear 24 & B-720 & B-727 & MD-11 & PA-30 \\
\hline Typical mid-fuel weight, lb & 35,000 & 11,000 & 140,000 & 160,000 & 359,000 & 3,000 \\
Wing quarter chord sweep, deg & 45 & 13 & 35 & 32 & 35 & 0 \\
Wing span, ft & 43 & 36 & 130 & 108 & 169.6 & 35.98 \\
Wing area, $\mathrm{ft}^{2}$ & 608 & 231 & 2,433 & 1,700 & 3,958 & 178 \\
Length, $\mathrm{ft}$ & 64 & 43 & 137 & 153 & 192 & 25.16 \\
Number of engines & 2 & 2 & 4 & 3 & 3 & 2 \\
Maximum thrust/engine & & & & & & \\
$\quad$ sea level static, lb & $13,000^{*}$ & 2,900 & 12,500 & 15,000 & 60,000 & $(160 \mathrm{hp})$ \\
\hline \hline
\end{tabular}

${ }^{*}$ F-15 engine at intermediate power

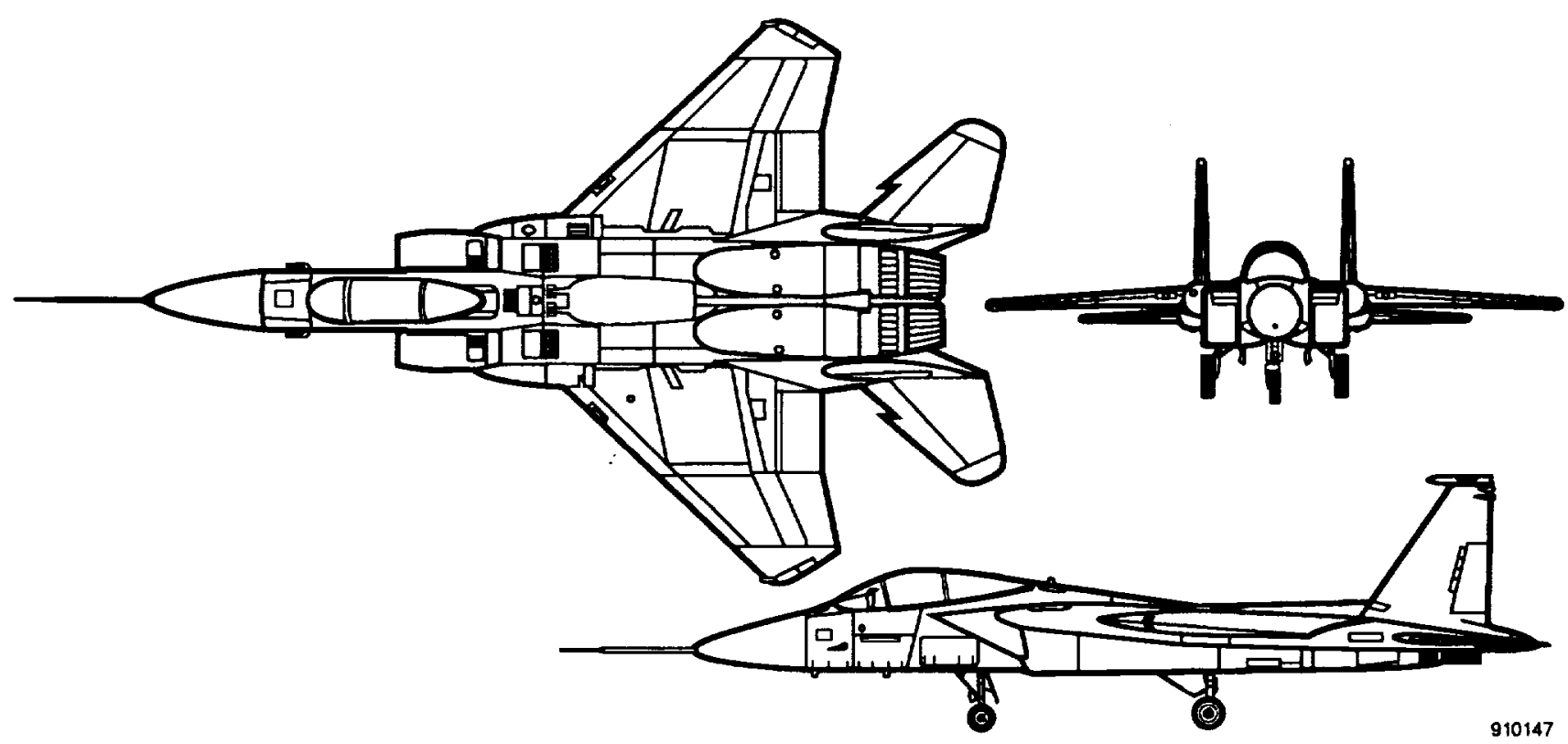

Fig. 1 The F-15 Air Superiority Fighter. 

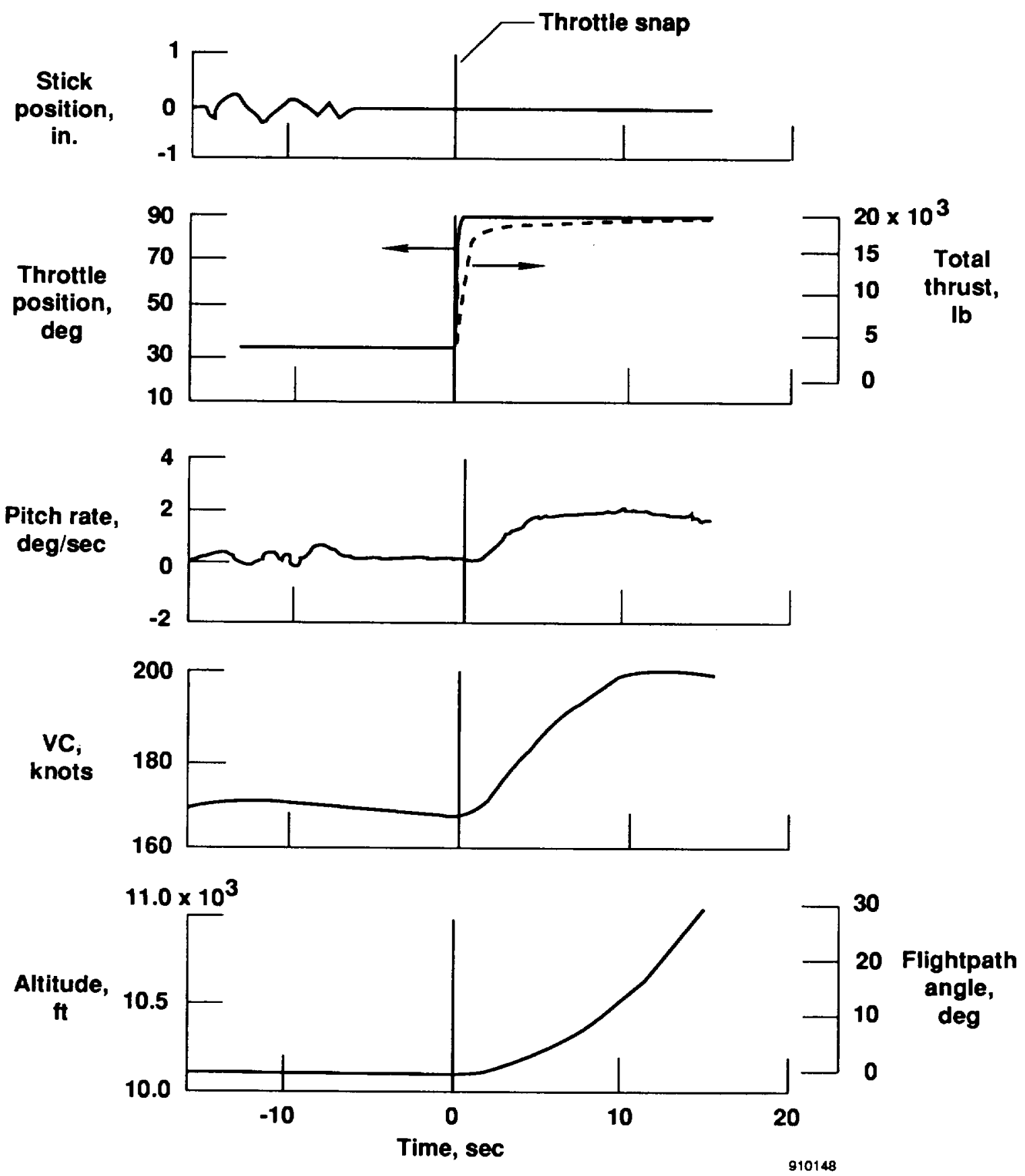

Fig. 2 Flight data time history of response to throttle increase from PLF to intermediate; F-15 airplane, CAS off, control stick free. 


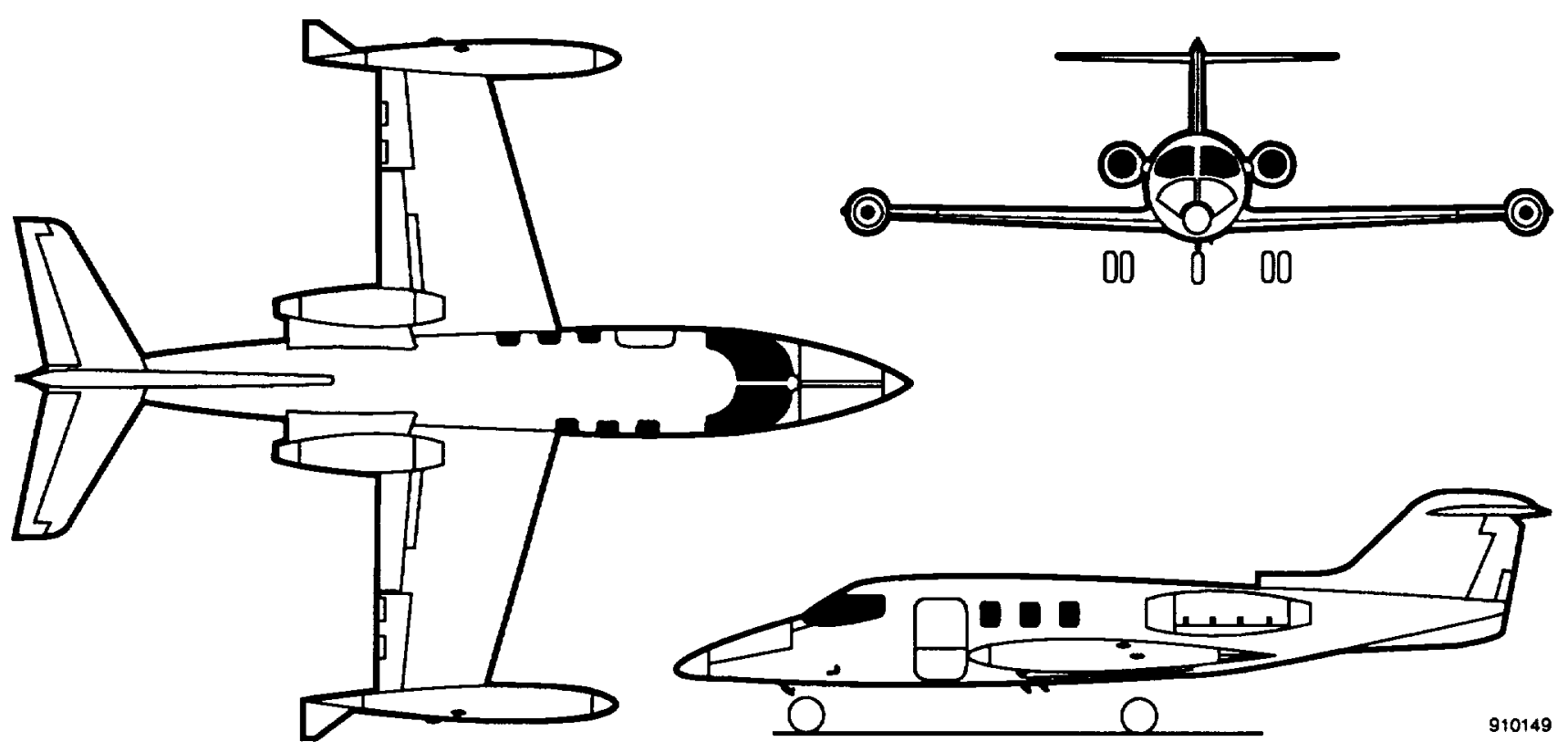

Fig. 3 The Lear 24 executive jet.
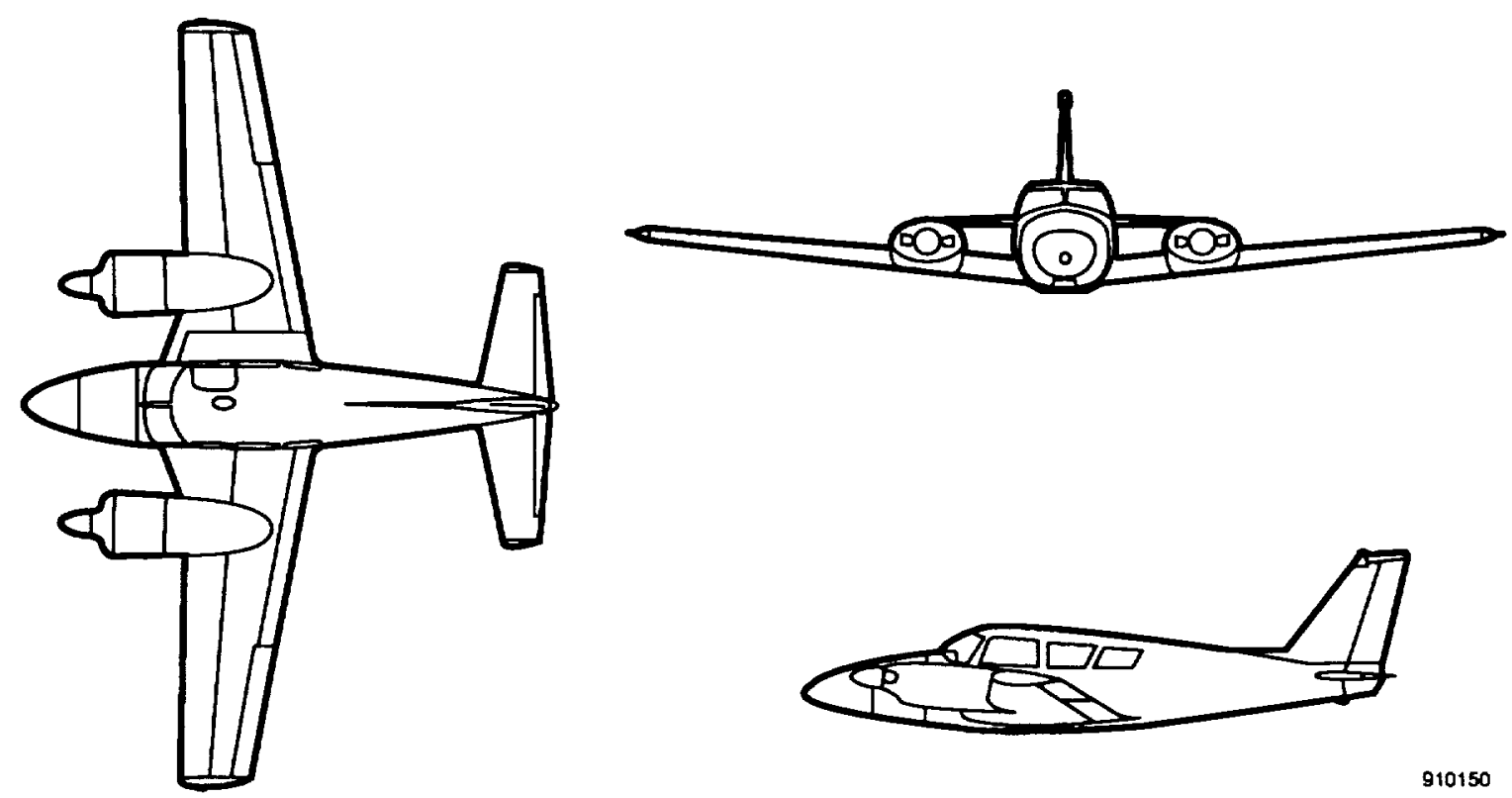

Fig. 4 The PA-30 light twin-engine airplane. 

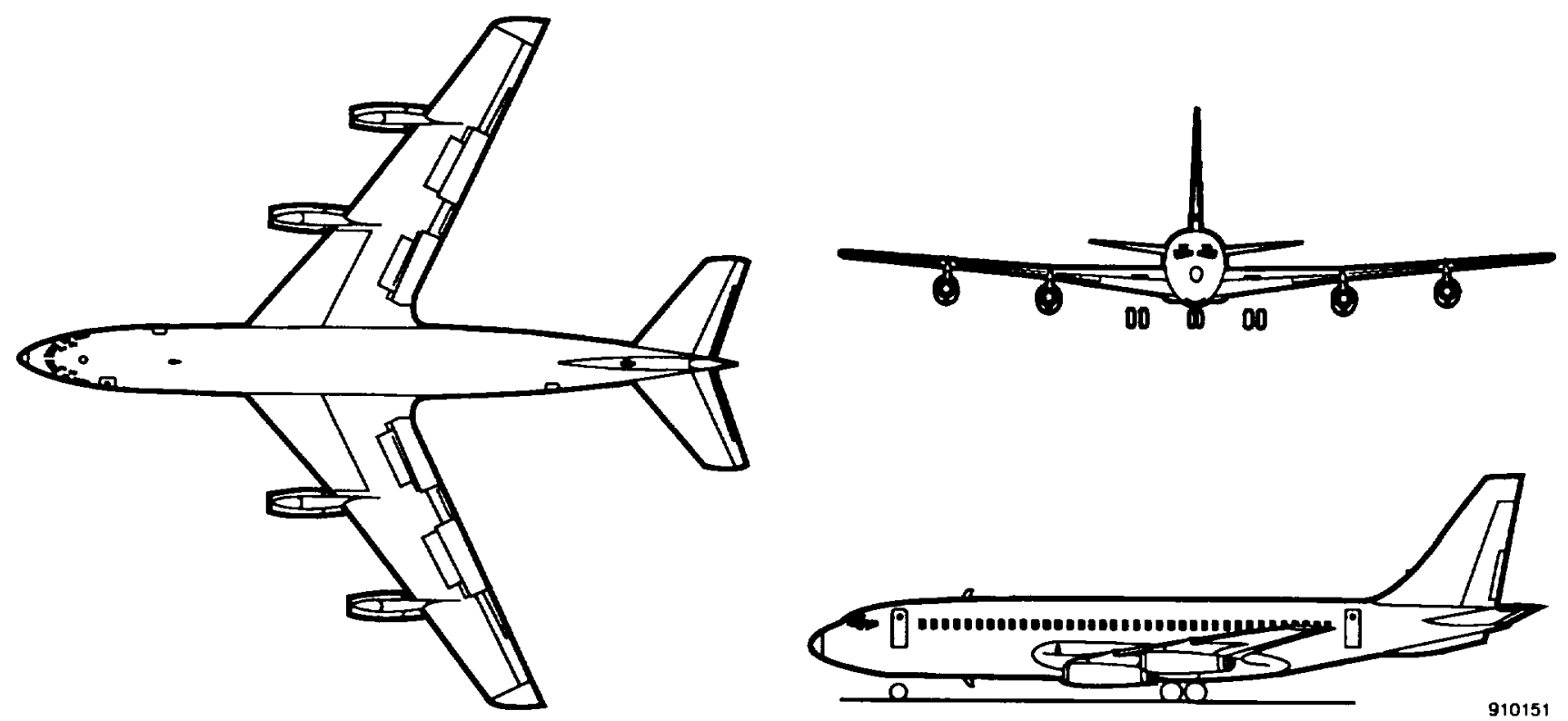

Fig. 5 The B-720 commercial jet transport. 


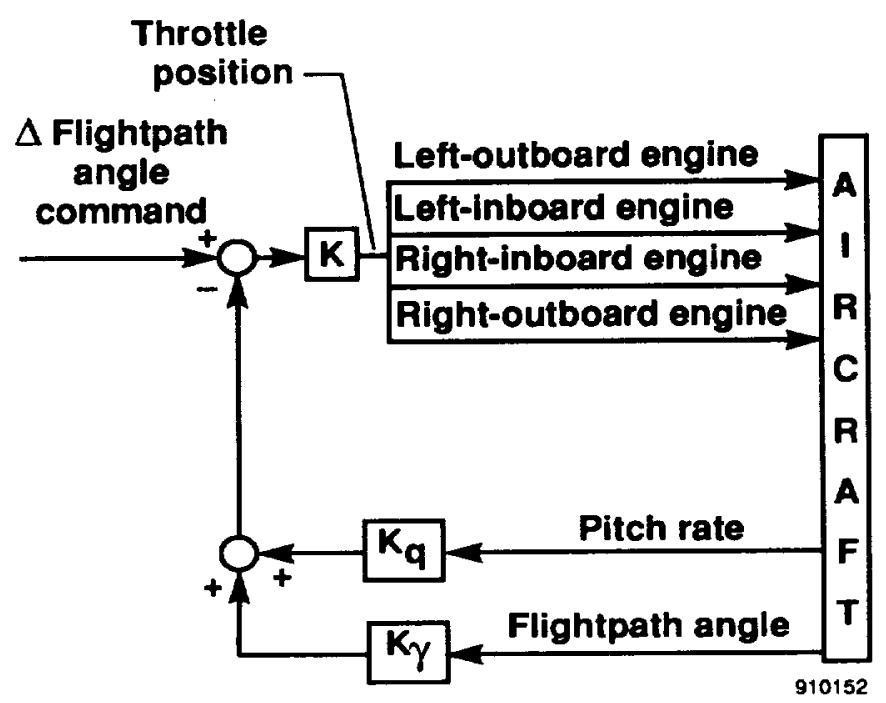

(a) Longitudinal control mode.

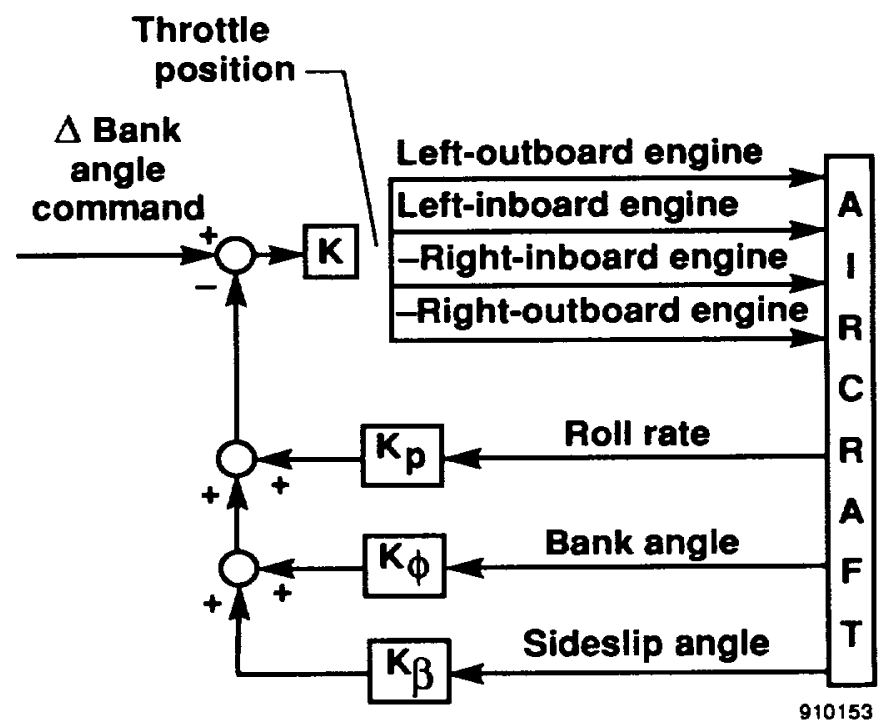

(b) Lateral control mode.

Fig. 6 The augmented throttles-only flight control system for the B-720 airplane. 


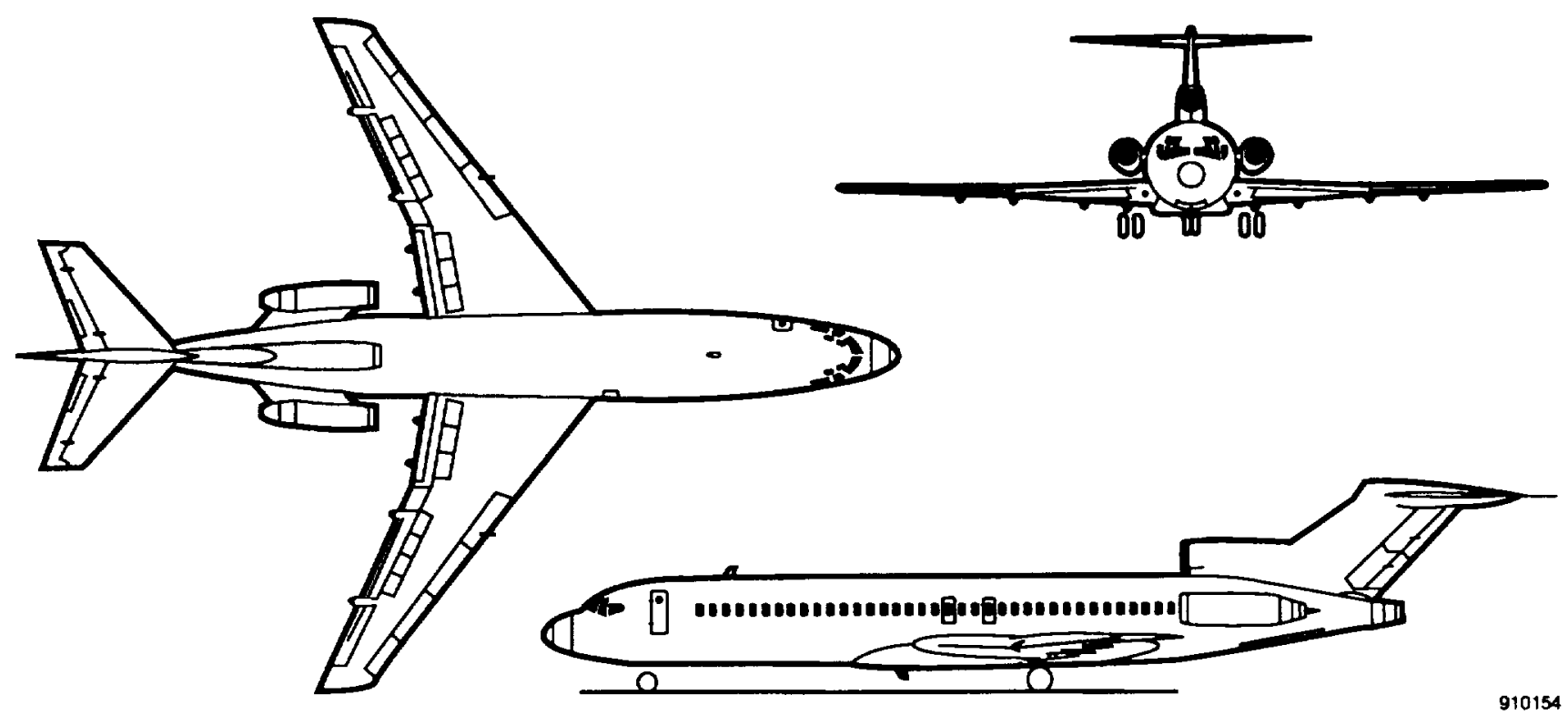

Fig. 7 The B-727 commercial jet transport.

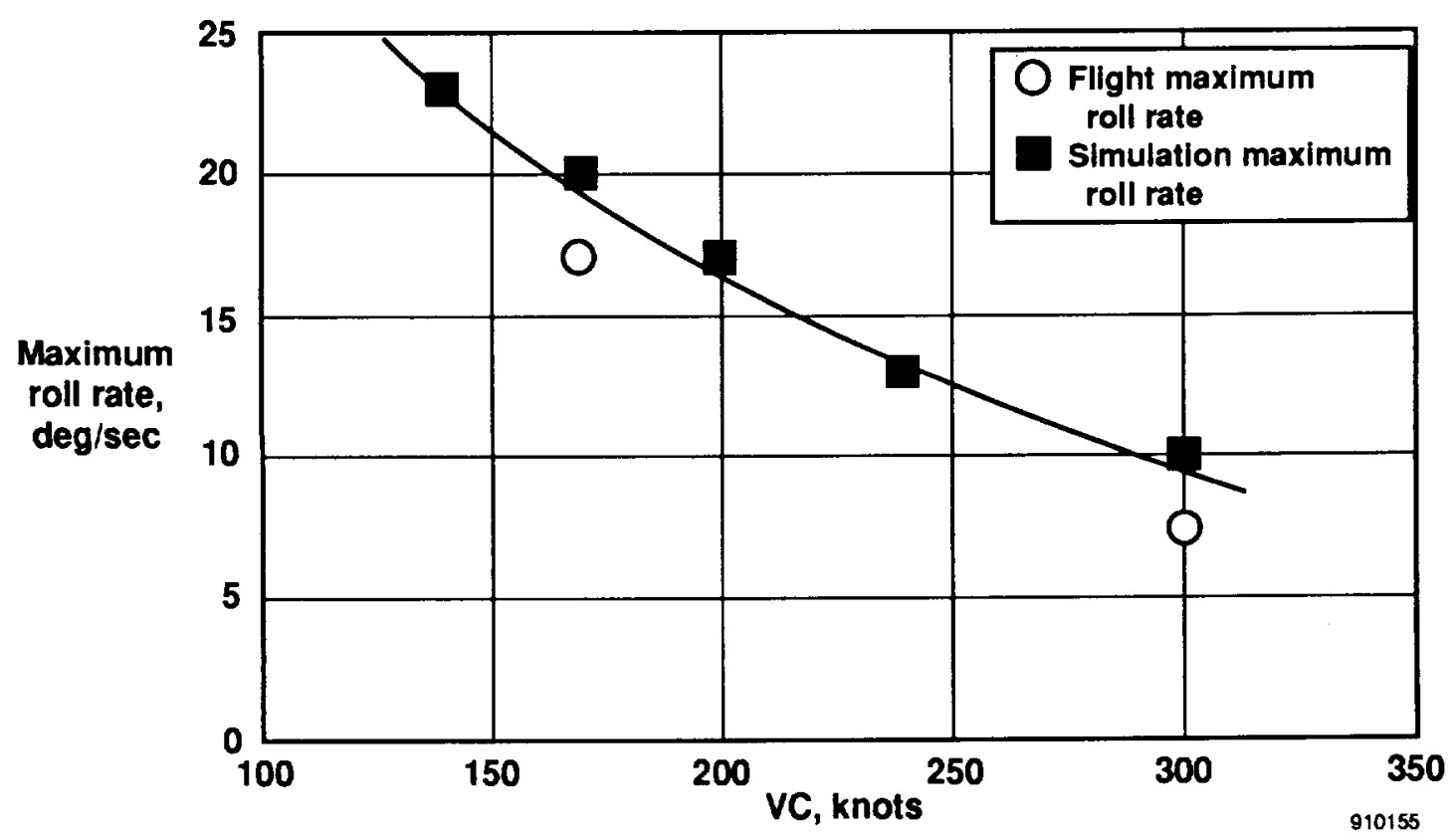

Fig. 8 Effect of VC on maximum roll rate, F-15 airplane and F-15 simulation, CAS off, left engine at intermediate power, right engine at idle. 


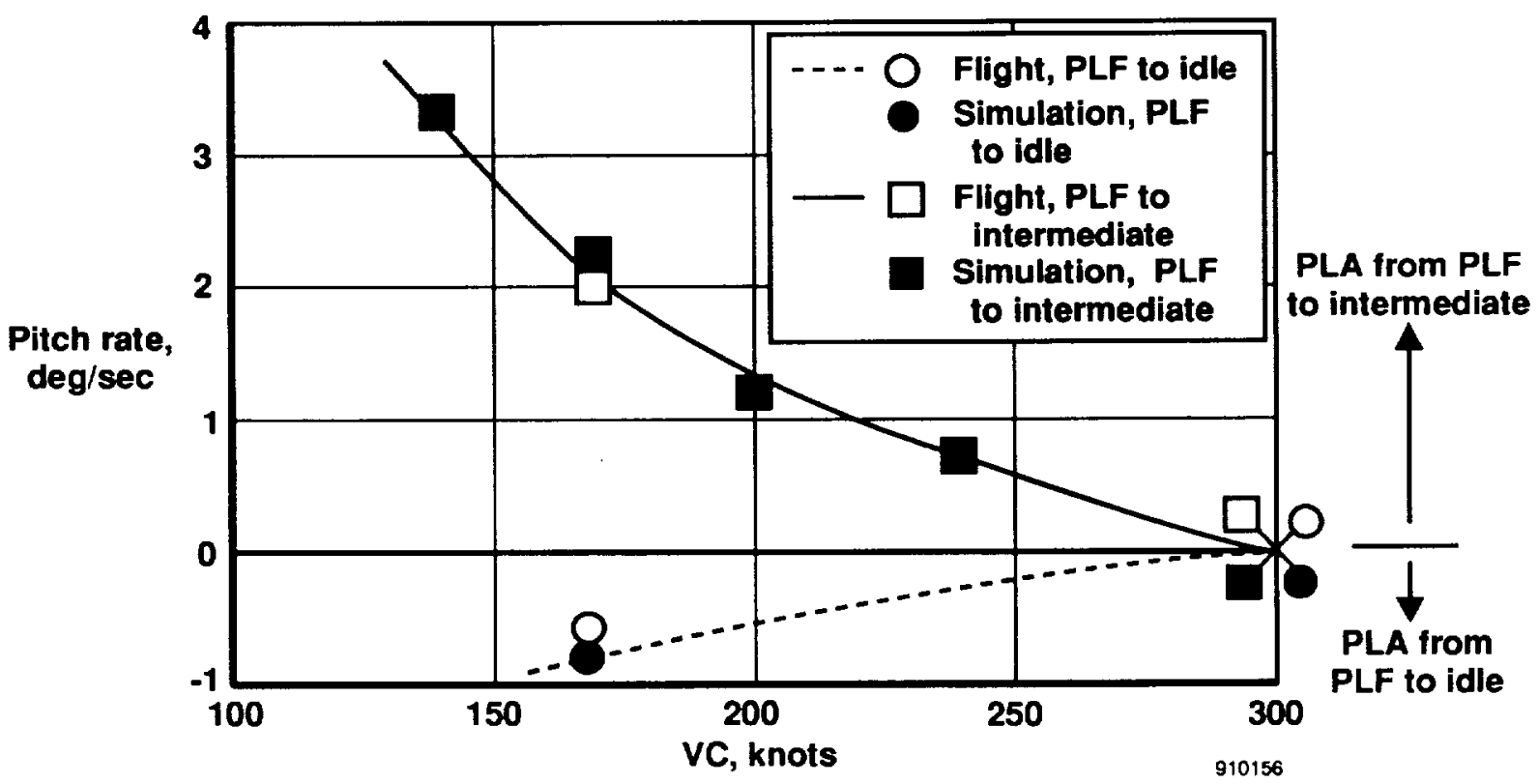

Fig. 9 Effect of speed on F-15 flight and simulation maximum pitch rates, CAS off.

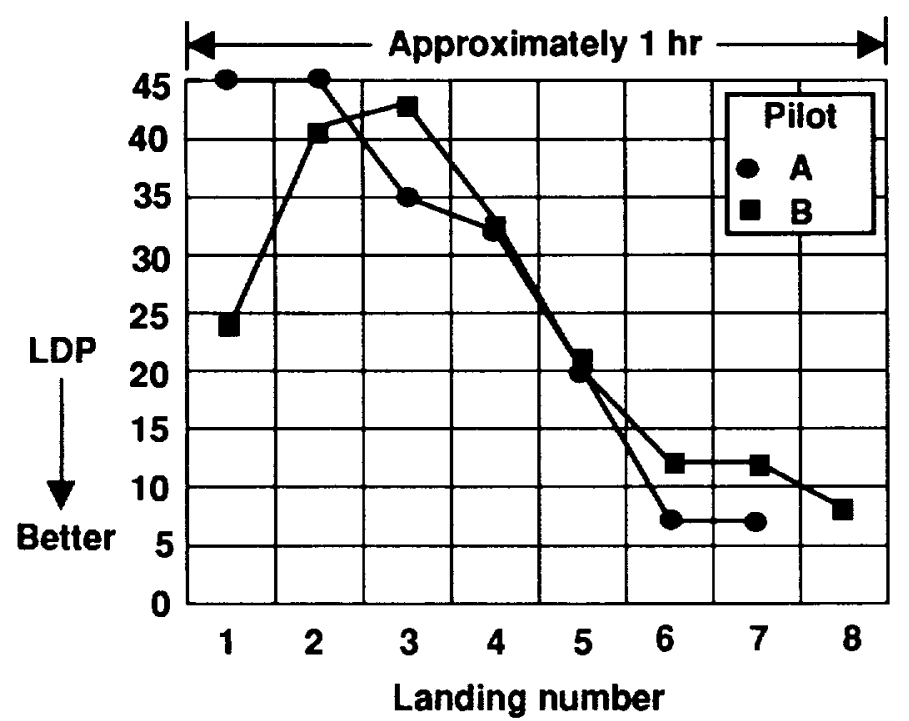

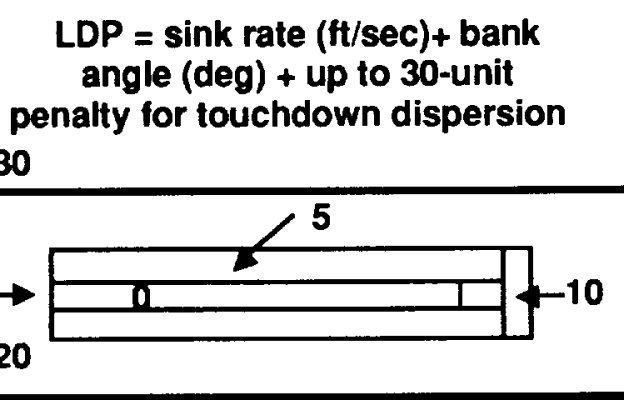

Touchdown dispersion penalty

Fig. 10 LDP for F-15 simulation flown with manual throttles-only control, trim airspeed of 170 knots. 

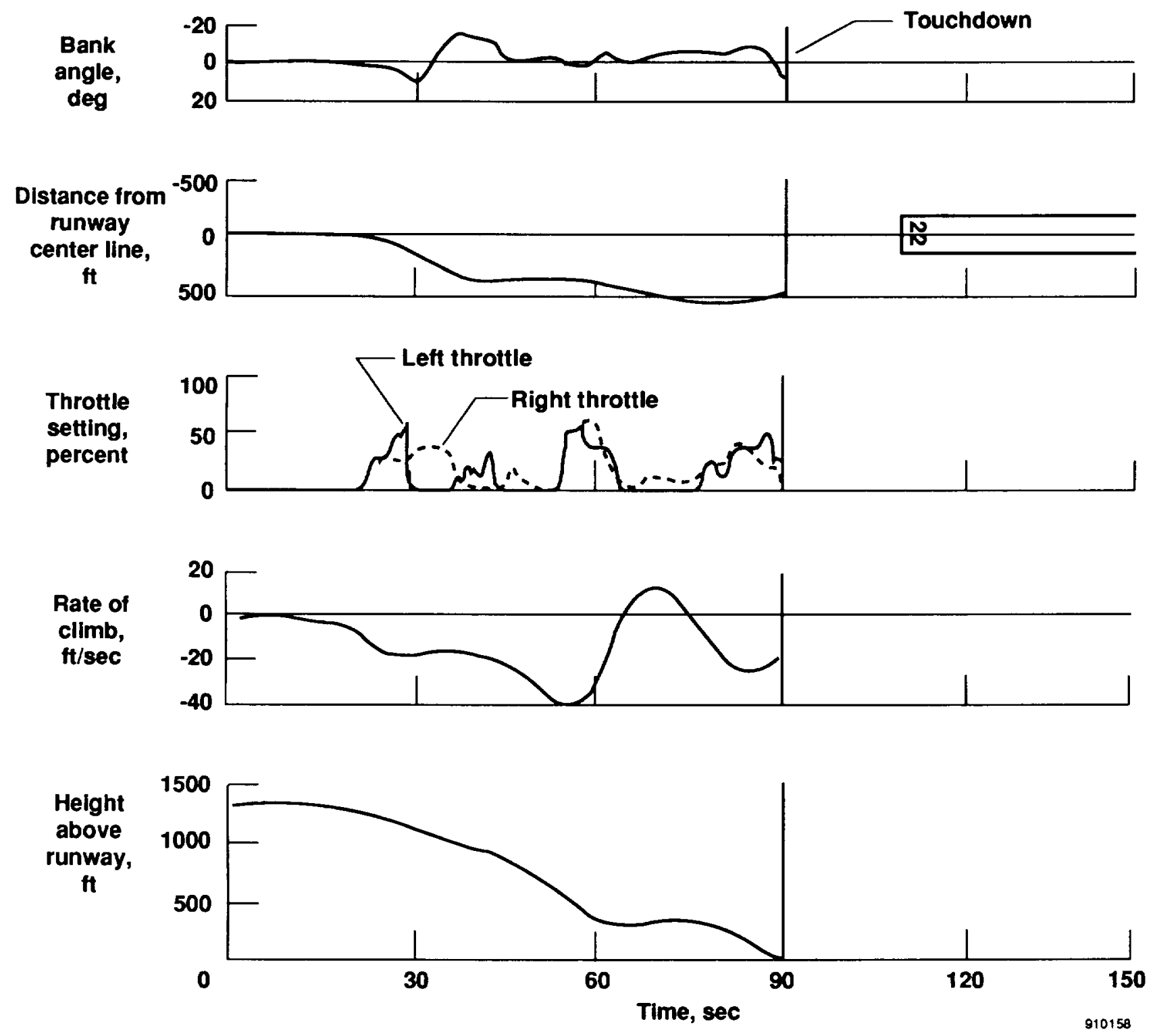

Fig. 11 Time history of throttles-only manual landing of the F-15 simulation, trim airspeed of 170 knots, pilot B's second landing. 

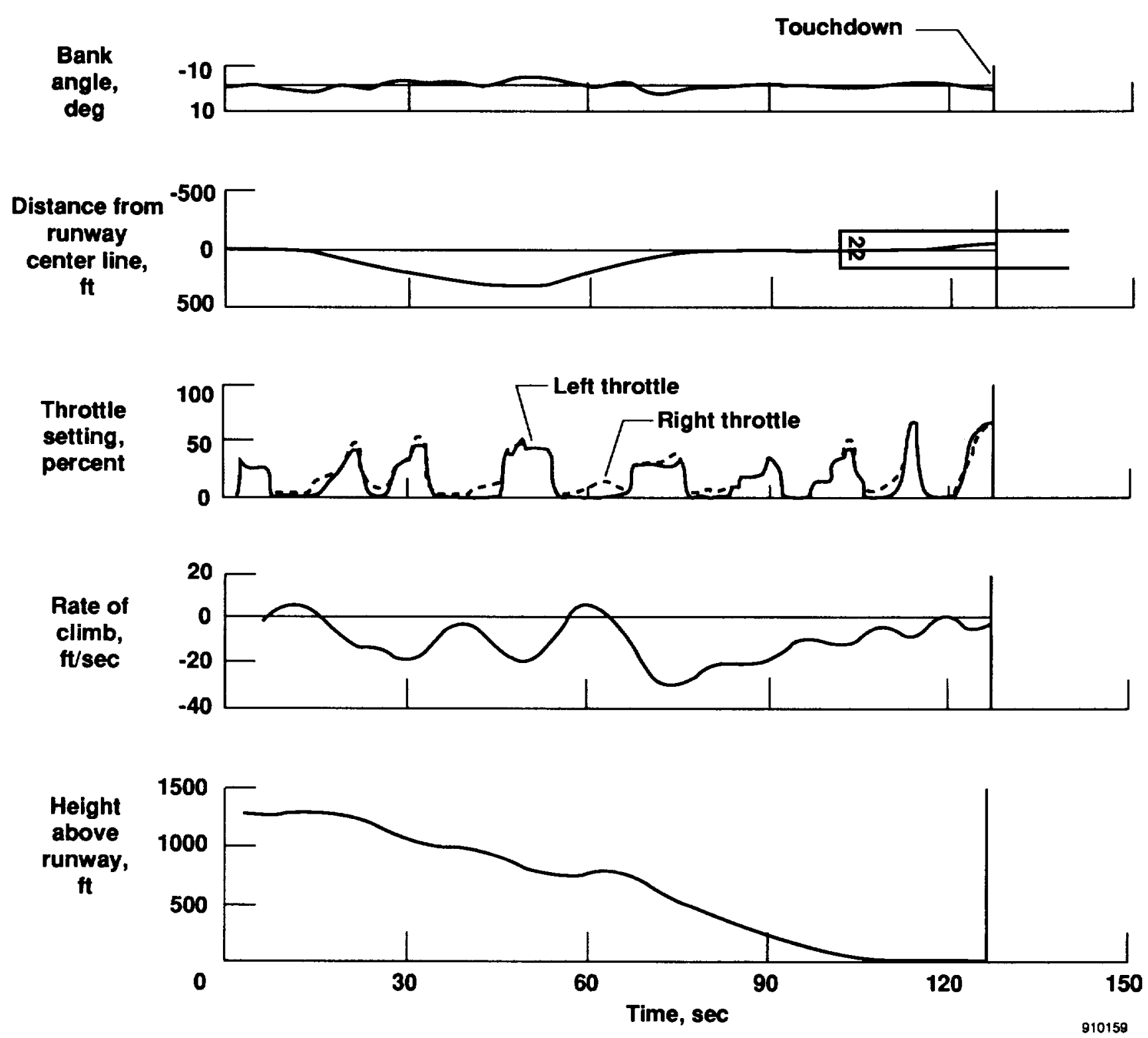

Fig. 12 Time history of throttles-only manual landing of the F-15 simulation, trim airspeed of 170 knots, pilot B's eighth landing. 


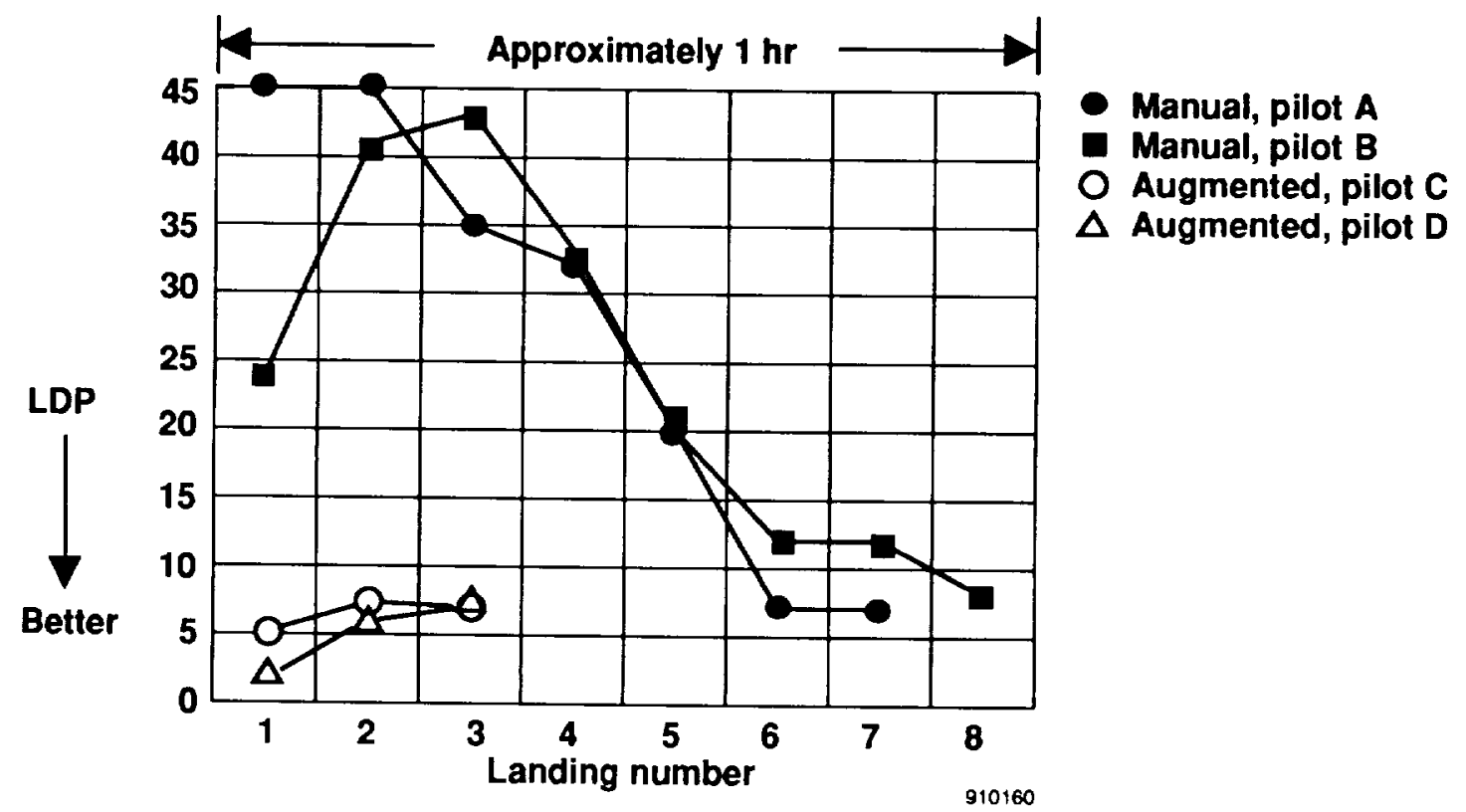

Fig. 13 LDP for F-15 simulation flown with augmented throttles-only control, trim airspeed of 170 knots. 

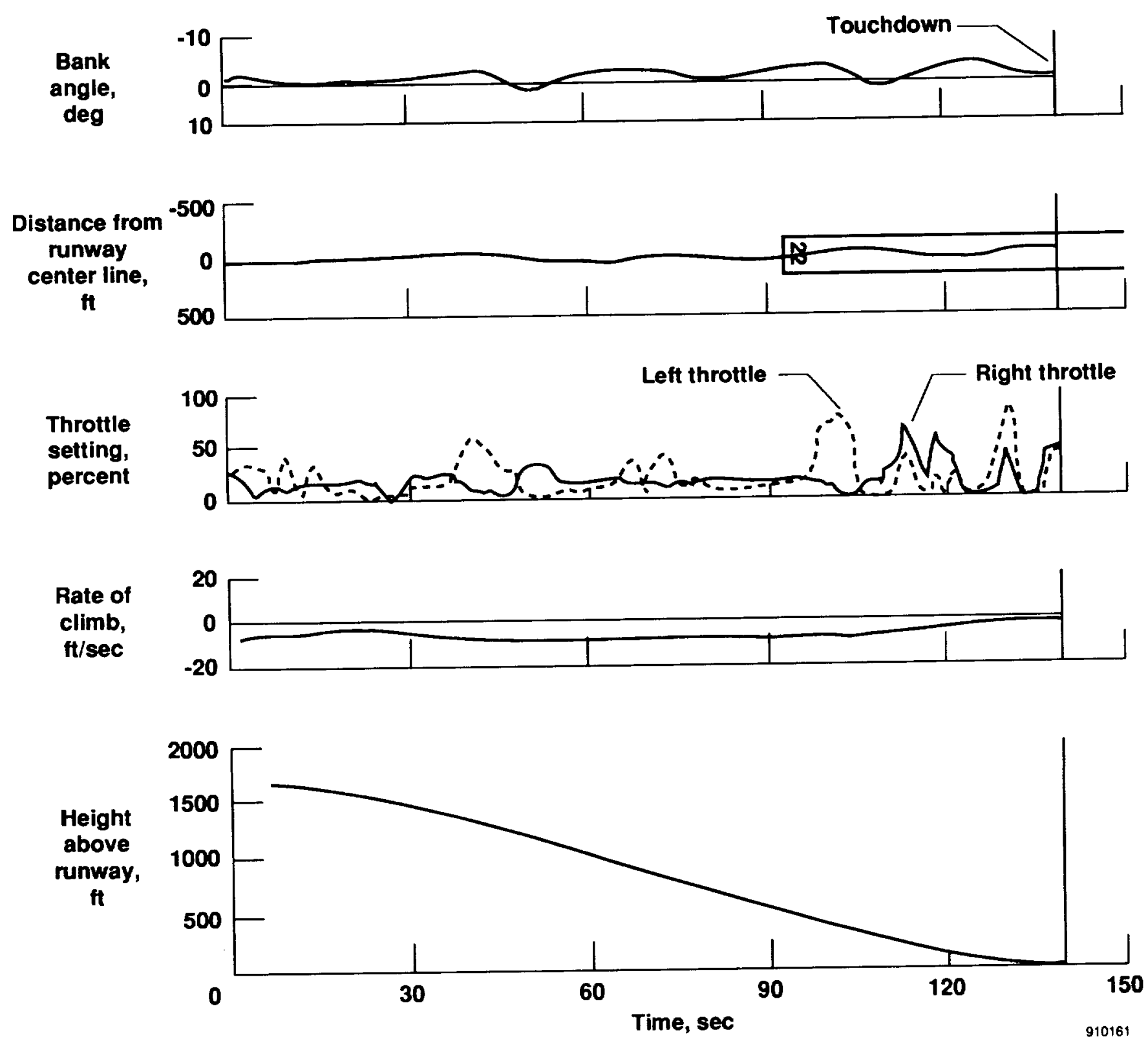

Fig. 14 Time history of augmented throttles-only landing of the F-15 simulation, trim airspeed of 170 knots; inexperienced pilot's first landing. 


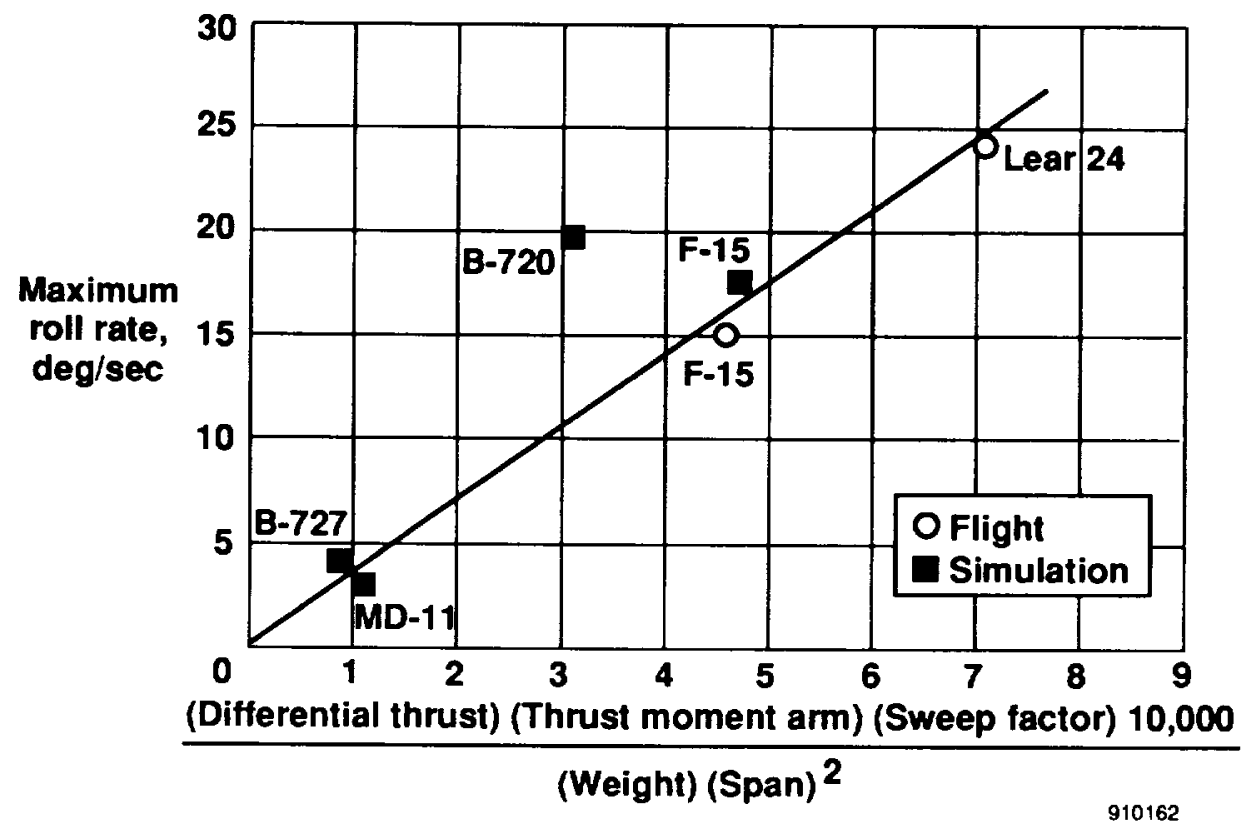

Fig. 15 Maximum throttles-only roll rate correlation for full differential thrust, trim airspeed of approximately 200 knots.

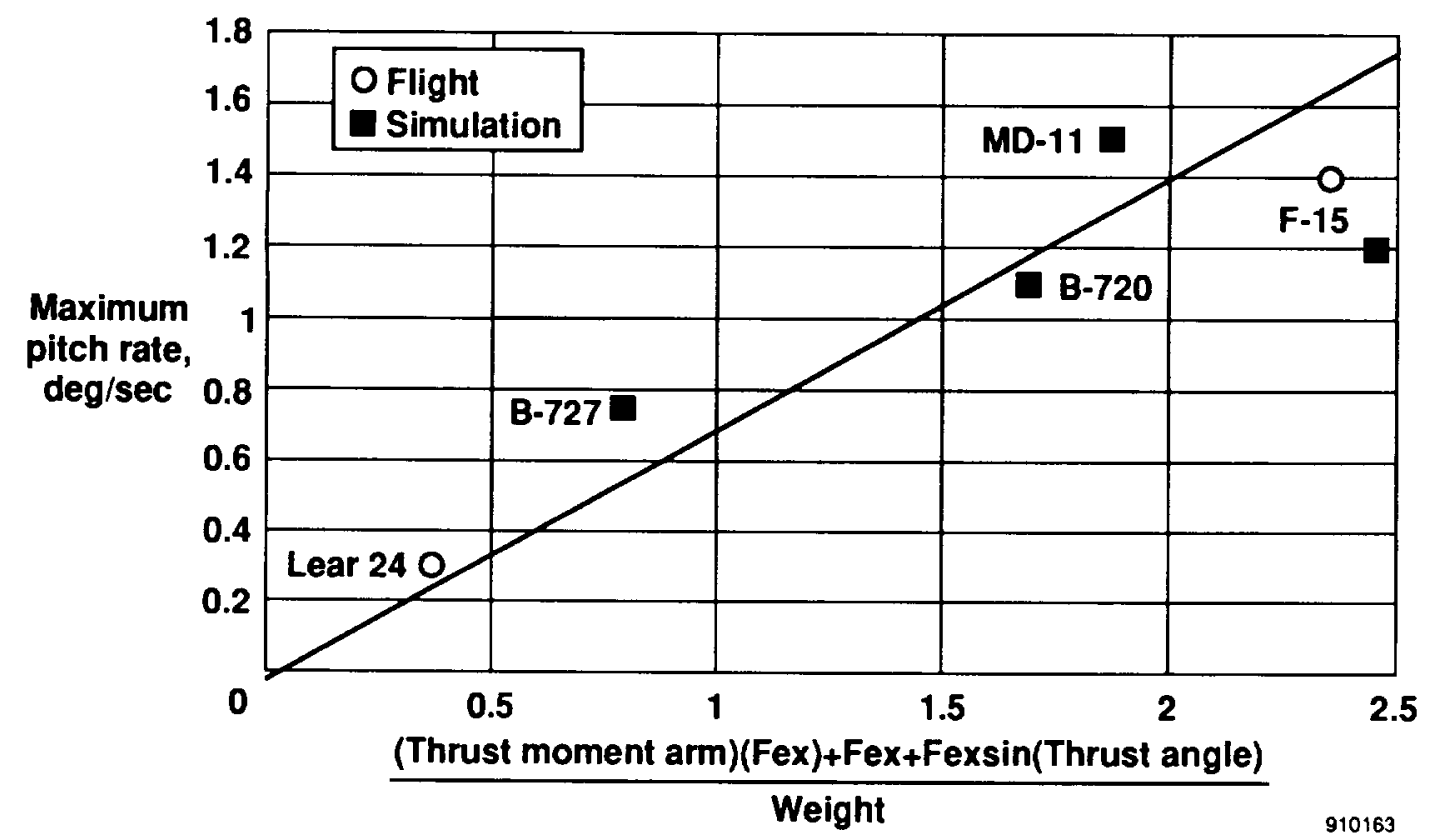

Fig. 16 Maximum throttles-only pitch rate correlation for full thrust, trim airspeed of approximately 200 knots. 


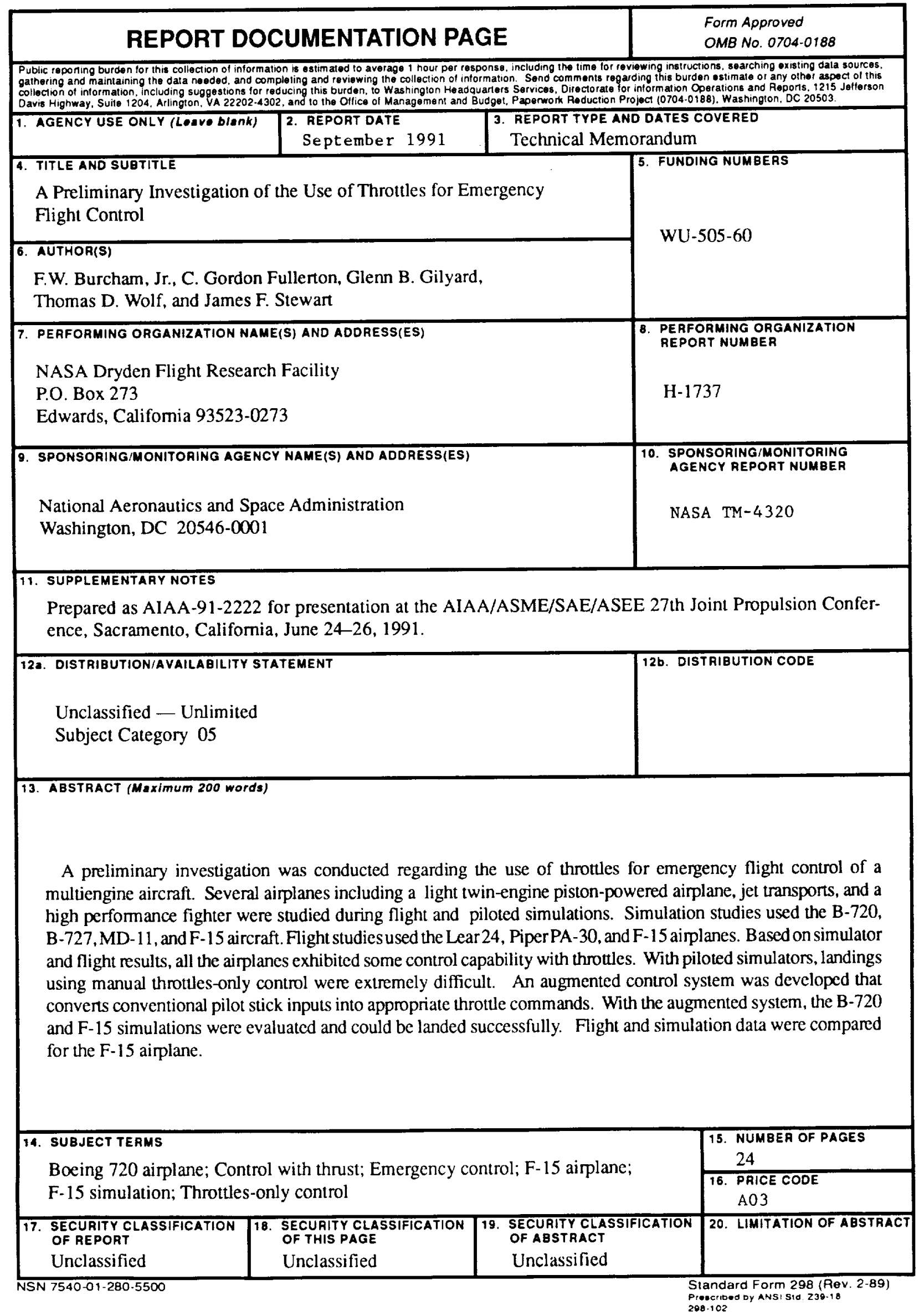

